\title{
Failure Analysis on Input Gear of a Gearbox
}

\section{Liu Changkui ${ }^{1, a}$, Zhang Bing ${ }^{1, b}$ and Chen Xing ${ }^{1, c}$}

\author{
${ }^{1}$ AVIC Failure Analysis Center, AECC Beijing Institute of Aeronautical Materials, Beijing 100095, \\ China \\ achangkuiliu621@163.com, bzhbenglish@126.com, cchenxing198411@163.com
}

\begin{abstract}
Keywords: Helical gear; Fatigue; Helicopter, Rould angle
Abstract. A tooth of the input helical gear of an intermediate gearbox in a helicopter fractured during testing. In order to find out the failure mode and cause, macro and micro observation, hardness and carburized depth testing, microstructure examination, surface roughness and round angle testing were carried out. The results show that the failure mode of the gear is fatigue failure. The crack initiated from the round angle of the tooth root at the working-face side. The round angle radius is smaller than the requried value, leading to the increase of stress concentration, which is the main cause for the fatigue fracture of the tooth. The machining process of the round angles should be concisely controlled so that such failure can be avoided.
\end{abstract}

\section{Introduction}

Helical gears have been widely used as power transmitting gears between parallel or crossed shafts, since not only can they carry larger loads but also the dynamic load and the noise level experienced during the operation are minimum.

Gears may fail in numerous different ways, and except for the increase in noise level and vibration, there is often no indication of difficulty until total failure occurs. In general, each type of failure leaves characteristic clues on gear teeth, and detailed examination often generates enough information to establish the cause of failure. The general types of failure modes (in decreasing order of frequency) include fatigue, impact fracture, wear and stress rupture[1]. Fatigue is the most common failure mode for gears. Several causes of fatigue failure have been identified, including poor design of the gear set, incorrect assembly or misalignment of the gears, overloads, inadvertent stress raisers or subsurface defects in critical areas, and the use of incorrect materials and heat treatments [1-4].

A tooth of the input helical gear of an intermediate gearbox for a helicopter fractured during testing. The input gear was made of $16 \mathrm{Ni} 3 \mathrm{CrMoE}$ steel. In order to find out the failure mode and cause, macro and micro observation, hardness and carburized depth testing, microstructure examination, surface roughness and round angle testing were carried out. and finally, corrective measures were put forward.

\section{Experimental}

\section{Macroscopic observation}

The appearance of the failed gear is shown in Fig.1. A crack with the length of about 50mm was found at the round anlge of a tooth root, and near the small end, a block had broken off. Obvious circumferential wear trace can be seen at the axle jornal, and the wear trace is near assembly region between bearing and axle jornal, as shown in Fig.2. Because the fit between bearing and axle jornal is interference fit, it can inferred that the circumferential wear trace resulted from inching wear. The macro apperance of the crack fracture surface is shown in Fig.3. The crack initiated from the working face at the round angle. The source is a small linear source. The macro apperance of the breaking-off block is shown in Fig.4. The source is a big linear source. 


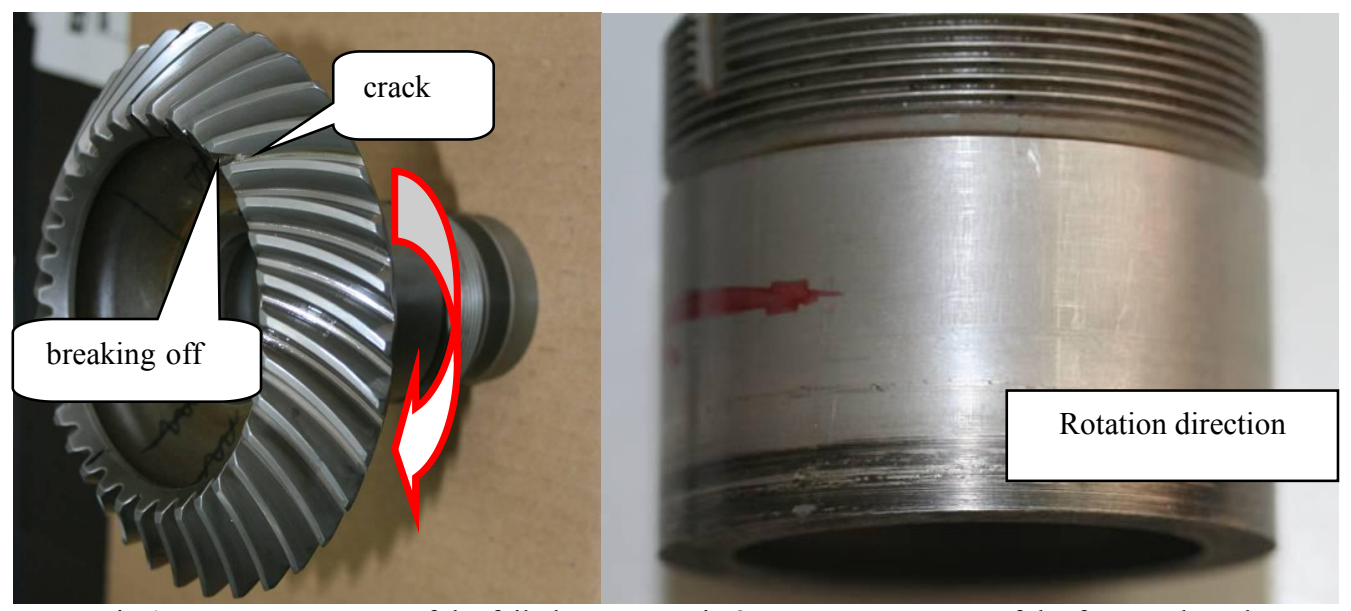

Fig.1 Macro appearance of the failed gear

Fig.2 Macro appearance of the fractured tooth

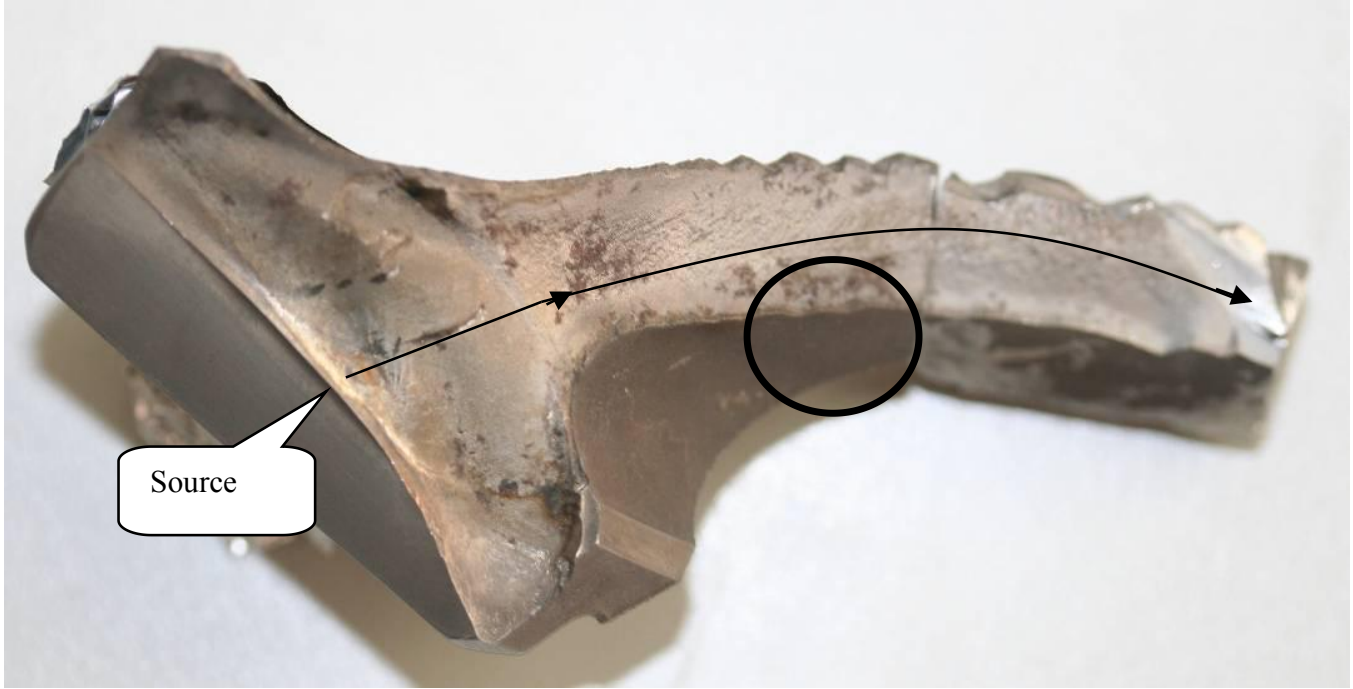

Fig.3 Macro appearance of fracture surface of the round-angle crack

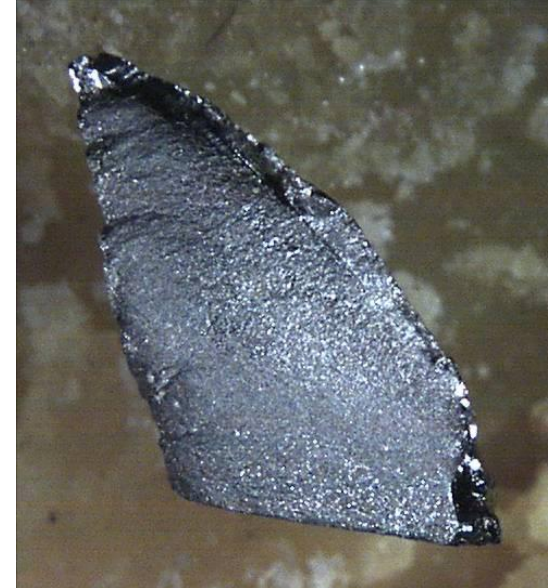

Fig. 4 Macro appearance of fracture surface of break-off block

\section{Microscopic observation}

The low-magnification appearance of the source region of the crack fracture surface is shown in Fig.5. The source is at a small line source and there are no obvious metallurgical defects at the source region. Machining trace can be found at the lateral face near the source, shown in Fig.6. The depth of the maching trace is about $1.5 \mu \mathrm{m}$ and the width is about $4.0 \mu \mathrm{m}$. Fatigue striations can be seen at the propagation region, shown in Fig.7. The man-made fracture region presents the characteristic of dimples, shown in Fig.8.

The black regions at the working face of other teeth present shelling-off feature due to serious wear, shown in Fig.9. EDS analysis results show that the oxygen content of these regions is about 4.7\%. At the working face near the top and at the top of some teeth, parallel wear trace can be seen, shown in 
Fig.10. During normal service, the top of the teeth of the output gear wouldn't be in contact with the bottom of the teeth of input gear. According to the parallel wear trace at the top of teeth, it can be assumed that axial float had happened to the gear. The parallel wear trace is shallow, short, and parallel, so it can be assumed that they formed a short time ago. Namely, they occurred after the tooth fractured. The direction of the working face wear trace of the teeth is the same as that of the top wear of the teeth, so it can also be assumed that they are also related to the axial float.

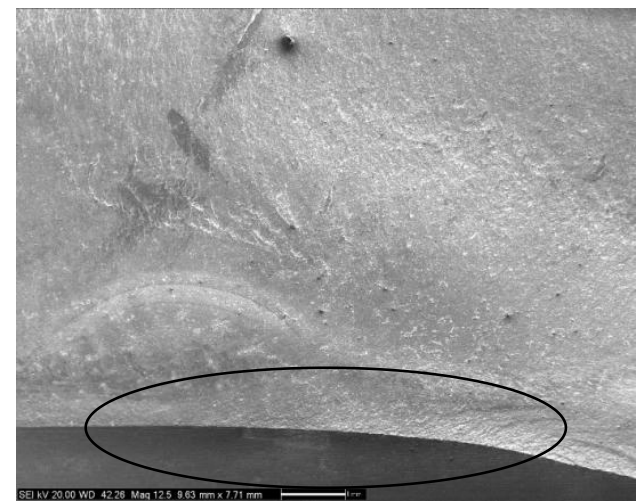

Fig.5 Low-magnification appearance of the source region of the crack fracture surface

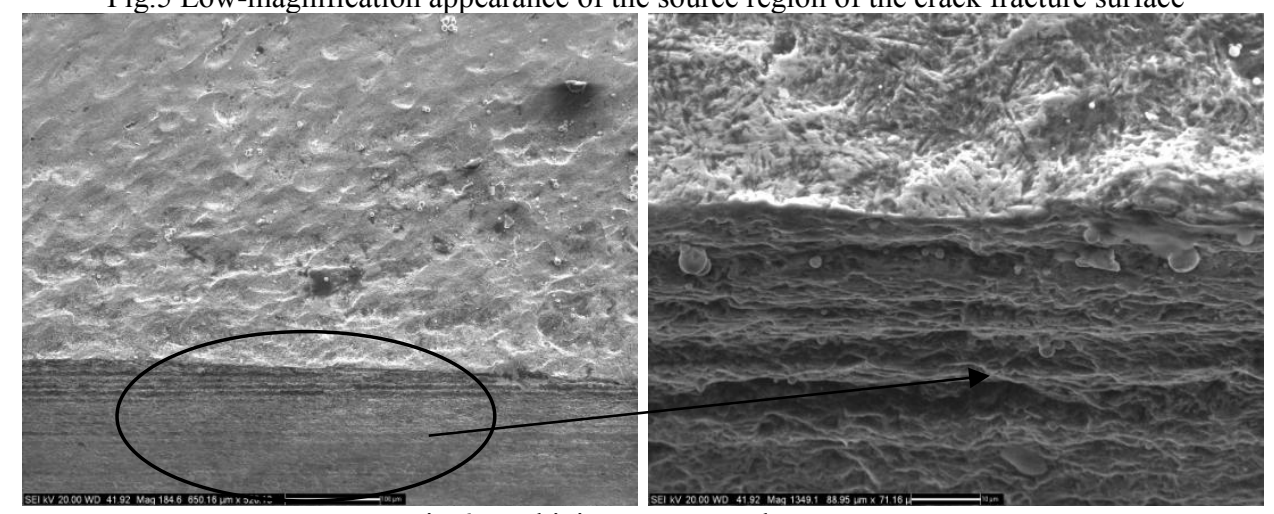

Fig.6 Machining trace near the source
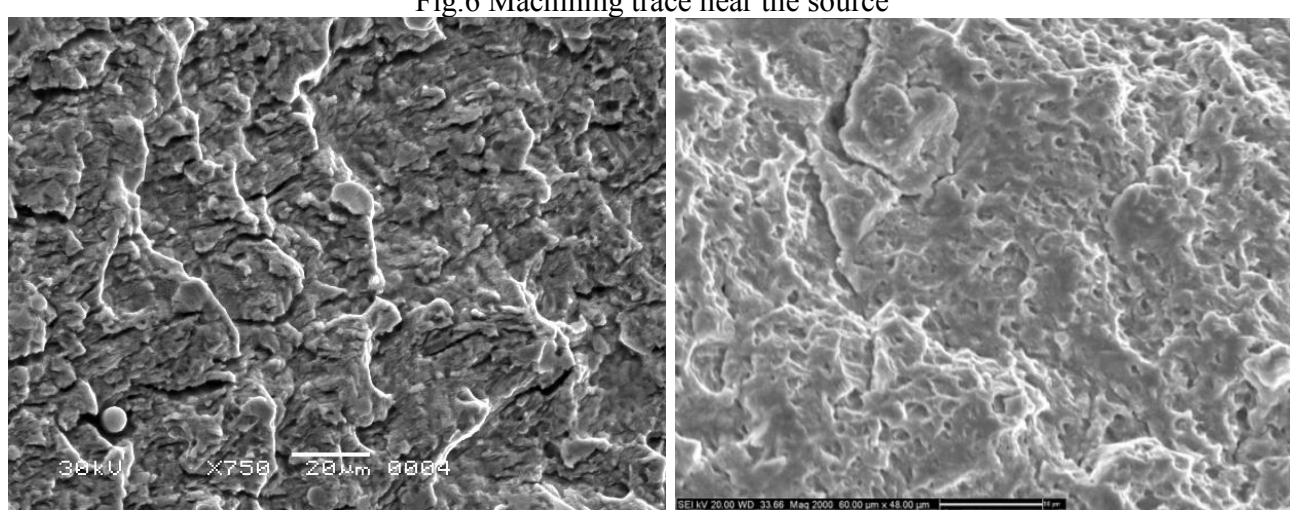

Fig.7 Fatigue striations at the propagation region Fig. 8 Dimples at the man-made fracture region

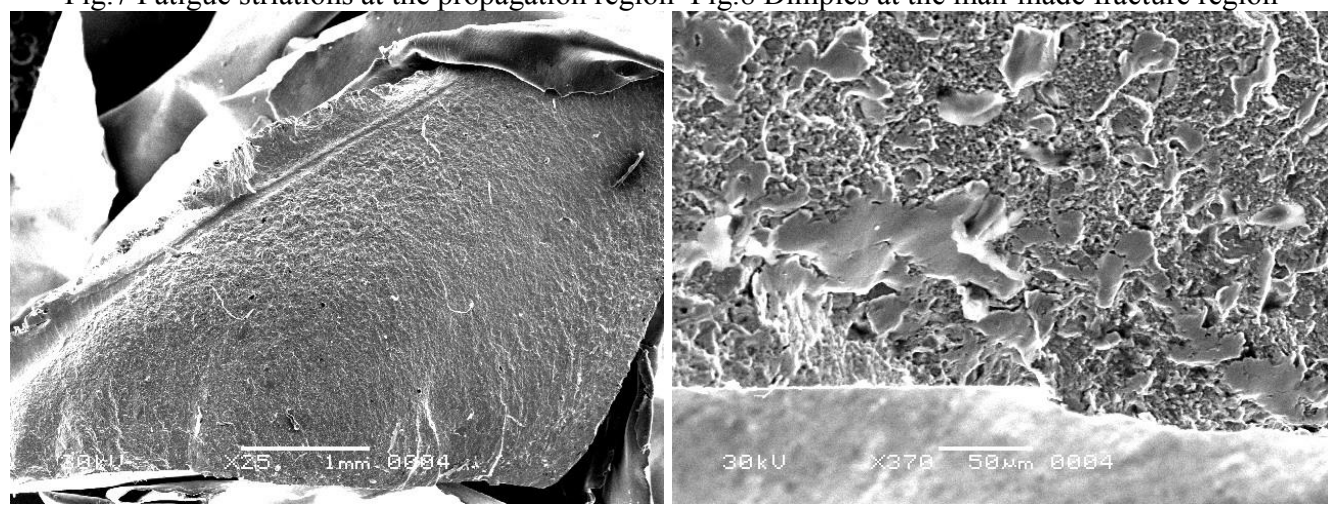

Fig.9 Low-magnification appearance of fracture surface of the breaking-off block

Fig.10 High-magnification appearance of the source 


\section{Quantitative analysis on fracture surface}

In order to figure out the crack propagation life, quantitative analysis on the crack fracture surface was carried out using the width of fatigue striations as a key parameter. Fatigue striations can be seen at the area $1.267-54.35 \mathrm{~mm}$ away from the source. The space between the striations at the propagation region was measured as fatigue propagation rate. Fatigue propagation life was obtained by listing trapezoidal method(Equation 1). The results show the fatigue propagation life is 57788 cycles. As for the breaking-off block, fatigue striations can be seen at the area $0.2 \mathrm{~mm} \sim 5 \mathrm{~mm}$ away from the source, and the the fatigue propagation life is 2954 cycles

$$
N_{f}=\sum N_{n}=\sum\left(a_{n}-a_{n-1}\right) /\left(\frac{\frac{d a_{n}}{d N_{n}}+\frac{d a_{n-1}}{d N_{n-1}}}{2}\right)
$$

Where an is the distance between the nth fatigue striation and the source, an- 1 is between the n- 1 th fatigue striation and the source, and $\mathrm{da} / \mathrm{dN}$ is the fatigue propagation rate(space between the striations).

\section{Microstructure examination}

Metallographic specimens perpendicular to the burn tooth face were cut down from the teeth near the fractured tooth. A burn surface layer can be seen, composed of sorbite(Fig.11). The core region is composed of lath-shaped martensite and residual austenite, shown in Fig.12. And there are only a small number of inclusions in the matrix, shown in Fig. 13.

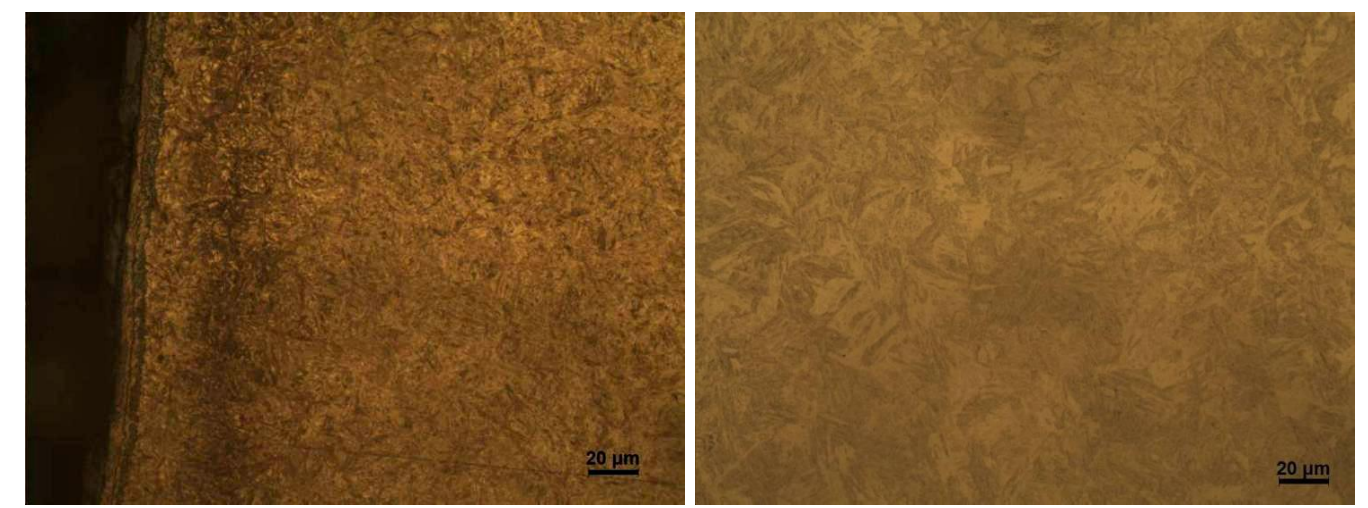

Fig.11 High-magnification burn structure near the surface Fig.12 Microstructure of core region of gear tooth

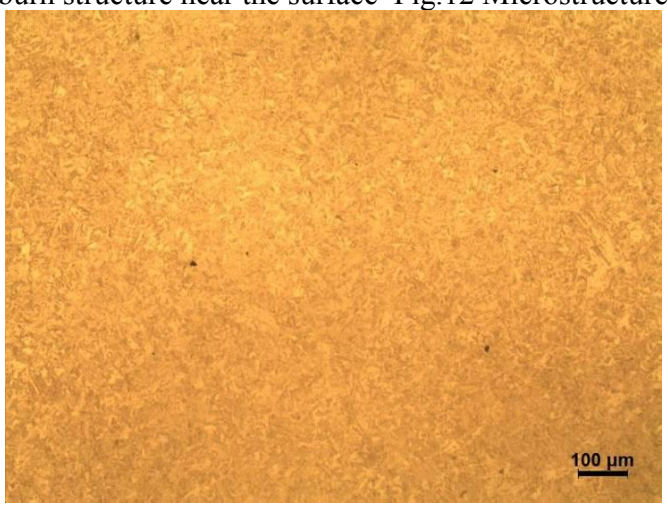

Fig.13 Inclusions in gear tooth

\section{Hardness and carburized depth testing}

Samples perpendicular to the working face were cut down from the teeth near the fractured tooth to test hardness and carburized depth. The hardness about $0.15 \mathrm{~mm}$ away from the surface is HV656 HV725, meeting the requirement $(\geqslant$ HV660). The core hardness of the gear is HRC42.39, within the required range of HRC $33 \sim \mathrm{HRC} 45$. The carburized depth of the working face is $1.285 \mathrm{~mm}$ 
and that of the round angle is $0.886 \mathrm{~mm}$. The carburized depth of the non-working face is $1.241 \mathrm{~mm}$, and that of the round angle is $0.958 \mathrm{~mm}$. They are all in the range of the required $0.8 \mathrm{~mm} \sim 1.6 \mathrm{~mm}$.

\section{Round angle measurement}

The round angle of four successive teeth near the fractured tooth were measured. The results are shown in Table 1. At the working face side, the round angle of three teeth is lower than the required R0.8 1. At the non-working face side, the round angle of one tooth is lower than the requirement.

Table 1 Measurement results of dedendum round angle

\begin{tabular}{|l|c|c|}
\hline \multicolumn{2}{|c|}{ Testing position } & Round angle value $\mathrm{R} / \mathrm{mm}$ \\
\hline \multirow{4}{*}{ Working face } & 1\# round angle & 0.551 \\
\cline { 2 - 3 } & 2\# round angle & 0.636 \\
\cline { 2 - 3 } & 3\# round angle & 0.814 \\
\cline { 2 - 3 } & 4\# round angle & 0.729 \\
\hline \multirow{4}{*}{ Non-working face } & 1\# round angle & 0.922 \\
\cline { 2 - 3 } & 2\# round angle & 0.679 \\
\cline { 2 - 3 } & 3\# round angle & 1.037 \\
\cline { 2 - 3 } & 4\# round angle & 0.941 \\
\hline
\end{tabular}

\section{Roughness measurement}

The roughness of the working face was measured. It is found that the roughness of working face, Ra, is $0.449 \mu \mathrm{m} \sim 0.522 \mu \mathrm{m}$, meeting the requirement $(\leqslant 1.6 \mu \mathrm{m})$.

\section{Discussion}

Based on fatigue striations at the two fracture surfaces, it can be assumed that the failure mode of the gear is fatigue cracking. The source of the crack facture surface is a small linear source, while that of the beaking-off block fracture surface is a big linear source. In addtion, according to the quantitative analysis results on fracture surface, the fatigue propagation life of the crack fracture surface is 57788 cycles, signficantly higher that of the breaking-off(2954 cycles). Therefore, it can be concluded that the initiation of the crack of the breaking-off block is later than that of the round angle of the tooth root.

Based on gear failure cases in the literature, fatigue fracture is the most common fracture mode, and most fatigue cracks originated at the surface or subsurface of gears, because the possibility for creating stress raisers, the key ingredient for fatigue crack initiation, is the greatest at the surface or subsurface. Pitting, sharp notches, surface deteriorations, poor machining and grinding marks are examples of stress raisers at the surface. Internally initiated fatigue cracks due to faulty materials and poor heat treatment practice, such as inclusions and other inhomogeneities, are rare[5-7].

In this case, the microstructure, hardness, carburized depth and roughness are all satisfactory and within the specification. However, the round angle of the working face of the gear teeth is smaller than required. During operation, the maximum tensile stresses occur at the root round angle at the working face side of the gear teeth, and the smaller round angle intersifies stress concentration, resulting in the initiation of fatigue crack. In addition, due to inching wear at the axle jornal, an additional vibration stress occrued, which promoted the iniation of fatigue crack. The machining process of the round angles should be concisely controlled so that such failure can be avoided, and the caused for the inching wear should be further analzed so that the inching wear can be avoided.

\section{Conclusion and recommendations}

The failure mode of the gear is fatigue failure. The crack initiated from the round angle of the tooth root at the working-face side. The round angle radius is smaller than the requried value, leading to the increase of stress concentration, which is the main cause for the fatigue fracture of the tooth. In addition, inching wear promoted the initiaon and propagation of the crack. The machining process of the round angles should be concisely controlled so that such failure can be avoided, and the caused for the inching wear should be further analzed so that the inching wear can be avoided. 


\section{References}

[1] Failure analysis and prevention. ASM handbook, vol. 11. Metals Park (OH): American Society for Metals; 1986.

[2] Fernandes PJL.Tooth bending fatigue failures in gears.Engineering Failure Analysis, 1996, $3: 219-225$.

[3] Asi Osman.Fatigue failure of a helical gear in a gearbox.Engineering Failure Analysis,2006,13(7):1116-1125.

[4] JIANG Rong-guo, LI Ruo-hui, ZHANG Guo-hui.Failure Analysis of Cracked Gear in Wind Power Gearbox. Failure Analysis and Prevention,2016,11(5):315-320.

[5] Samroeng Netpu, Panya Srichandr. Failure of a helical gear in a power plant.Engineering Failure Analysis,2013,32:81-90.

[6] Martin R, Karen S. Fatigue failure of carburized steel gear from a helicopter transmission. In: Handbook of case histories in failure analysis. OH: ASM International; 1992. 228-230.

[7] Becker WT, Shipley JR, editors. Failure analysis and prevention, ASM handbook, vol. 11. OH: ASM International; 2007. 718-720. 